\title{
Special Issue on the Economics of Food Assistance Programs
}

\author{
David R. Just
}

Given the confluence of growing budget deficits, increasing rates of poverty, and historically high rates of obesity, food assistance programs have become a highly contested topic. As the debate surrounding the new Farm Bill heats up, food programs have become a point of contention. More than two-thirds of Farm Bill spending goes to food assistance of some sort-with spending on food stamps, in particular, far exceeding the projected budgets over the last four years. Many have questioned the proper role for government in ensuring access to food among those of lower income, while encouraging healthier eating habits. These programs impact large portions of the U.S. population-close to 50 million participate in the Supplemental Nutrition Assistance Program (SNAP, the program formerly known as food stamps), and more than 30 million participate in the National School Lunch Program (NSLP) on a daily basis. Much of the recent debate centers on whether these programs should stick to their historical goal of reducing hunger, or take on an additional and competing goal of reducing obesity.

In order to address the growing questions about the effectiveness of food assistance programs and their impact on obesity and nutrition, we have assembled this special issue of the Agricultural and Resource Economics Review. The majority of these papers were originally presented as part of the Agricultural and Applied Economics Association (AAEA) and Northeastern Agricultural and Resource Economics Association's (NAREA) workshop on the Economics of Food Assistance Programs, held in Pittsburgh, Pennsylvania, in July 2011. The goal of this workshop was to showcase emerging issues and creative policy solutions in nutrition and food programs. We express our thanks to the U.S. Department of Agriculture's
Economic Research Service, the Cornell Center for Behavioral Economics in Child Nutrition Programs, and the Food Safety and Nutrition section of the AAEA for their support of this workshop. Additionally, we have included the valedictory of the distinguished scholar Ronald W. Cotterill. His work describing the history and direction of food marketing research was delivered as he received NAREA's award for Outstanding Public Service.

Half of the articles comprising this special issue address the NSLP and its impact on health. This September, the USDA will implement new guidelines for school lunches eligible for the NSLP. These new guidelines are designed to increase fruit and vegetable consumption, and reduce consumption of fat, starch, and sodium. Constance Newman provides a timely and important analysis of the potential costs this may impose on schools as they seek to meet the new standards. David Conner, Betty Izumi, Toni Liquori, and Michael Hamm build on this work by examining the procurement of food in the NSLP. Two papers - one by David Just, Joseph Price, and Jesse Lund, and the other by Andrew Hanks, David Just, and Brian Wansink-address the impact of food offerings (both variety and by individual foods) on food selection and consumption by school lunch participants. Finally, Joshua Price examines the impact of vending machine sales on school behavioral issues.

Other works examine the impacts of SNAP or broader issues of access to food, obesity, and food marketing. Rebecca Burgstahler, Craig Gundersen, and Steven Garasky use secondary data analysis to examine the potential links between SNAP participation and childhood obesity, controlling for financial stresses that have otherwise been linked to obesity. This work goes a long way in addressing the plausibility of using SNAP to 
achieve the dual goals of food security and a reduction in obesity. A pair of papers examine the impact of food price and income on consumption. Patrick Hatzenbuehler, Jeffrey Gillespie, and Carol O'Neil examine whether a reduction in competition among poor areas (so-called food deserts) leads to disparity in food pricing. Susan Chen, Jing Liu, and James Binkley examine the impact of income on consumption of milk and sodatwo similarly priced substitutes with widely different nutritional values. Joshua Berning uses secondary data analysis to examine whether ac- cess to local foods (e.g., through a farmers market) impacts the level of obesity of those living in the surrounding area. Finally, Collin Payne and Mihai Niculescu examine the potential use of social meaning and marketing strategies to lead parents to purchase healthier food for their children.

As the organizer of this workshop and special issue, I would like to thank the authors for their participation and cooperation. I would also like to congratulate them on their substantial contributions to food assistance policy. 